\title{
Karyocytomegaly and Multinucleated Hepatocytes
}

National Cancer Institute

\section{Source}

National Cancer Institute. Karyocytomegaly and Multinucleated Hepatocytes. NCI

Thesaurus. Code C120895.

A finding of both karyocytomegaly and multinucleated hepatocytes in the same lesion. 